\title{
Hegemonía o alternancia: trayectorias glocales de la antropología
}

\author{
Carmen Bueno
}

GUSTAVO LINS RIBEIRO Y ARTURO ESCOBAR (eds.), 2006 World Anthropologies: Disciplinary Transformations within Systems of Power

The Wenner-Gren Foundation, Berg, Nueva York (Wenner-Gren International Symposium Series).

E sta es una obra que todo antropóClogo debería leer. Se trata de hacer antropología de las antropologías del mundo. De conocer la complejidad, magnitud y variedad del quehacer de nuestra disciplina. De presentar su proceso evolutivo en diversos países de los cinco continentes que integran este planeta. Las discusiones giran en torno al origen, difusión, complementariedad, mutación y/o confrontación de diversas tradiciones antropológicas
— estas últimas siempre circunscritas a las condiciones del entorno y al respaldo institucional con el que han contado, lo cual influye significativamente en las restricciones, tensiones, contradicciones y oportunidades de desarrollo_- Las trayectorias particulares de las antropologías del mundo nos muestran la capacidad que tiene nuestra disciplina de transformarse a sí misma. Cada vez, en múltiples combinaciones, emerge, muere y
Hegemony or Alternance: Anthropology's Glocal Trajectories

CARMEN BUENO: Universidad Iberoamericana, México-Distrito Federal. carmen.bueno@uia.mx

Desacatos, núm. 25, septiembre-diciembre 2007, pp. 238-242.

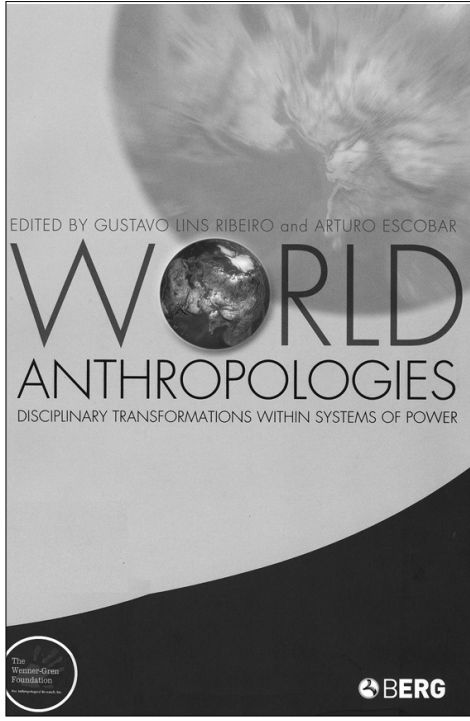

renace, redefiniendo sus intereses y propósitos.

El libro nos muestra la manera plural en que los otros saberes, cuando emergen, se encuentran y desencuentran con el conocimiento hegemónico. Por ello, sus autores no sólo presentan una reflexión epistemológica de la transformación de la antropología en diversas partes del mundo, sino que además dan cuenta de la creación de 
campos de poder que legitiman, segregan o subsumen el conocimiento, así como de proyectos nacionales que promovieron el desarrollo de un pensamiento crítico, o por el contrario, de otras antropologías que acompañaron proyectos imperialistas y transnacionales, contribuyendo de esa manera a legitimar el colonialismo de los países centrales.

Este libro se compone de cuatro partes. En la primera, titulada "Transnacionalismo y poder del Estado", se presentan las antropologías de Japón, Siberia, China y México. En la segunda se tratan temas de poder y hegemonía a partir del desarrollo antropológico de Francia, España y África. La tercera parte se refiere a los predicamentos epistemológicos, sociológicos y disciplinarios de las antropologías británica, andina, australiana y de la India. La cuarta y última parte, titulada "De las antropologías de hoy a las antropologías del mundo", expone, además del caso de la antropología brasileña, más que una síntesis y conclusiones, una serie de preguntas para el futuro.

El tema más recurrente de la antropología en diferentes partes del mundo es lo étnico. Llama la atención que el conocimiento de las raíces culturales ha cumplido diversos propósitos. Por ejemplo, la antropología desarrollada en Siberia en el siglo XIX comenzó con un interés puramente científico por la geografía humana de esa región nórdica y después fue utilizada por el régimen soviético para diseñar políticas hacia las etnias y sus lenguas. Japón, con base en una suerte de estudio interdisciplinario con la biología, registró la variedad étnica de esa nación y su manifestación en el folclor. En México, el estudio de su pluralidad étnica está profundamente enraizado en la búsqueda de identidad de la nación mexicana, en combinación con la conservación del patrimonio colonial y prehispánico.

Australia se interesó por la cultura de los aborígenes con el propósito de comprender los principios relativos a la propiedad y la herencia de la tierra. En la región andina el estudio de la diversidad étnico-cultural se encuentra inmerso en el debate sobre el mestizaje y la interculturalidad, cuya finalidad es generar una agenda política propia. El estudio de las minorías étnicas fue prioritario en la antropología china como parte de las políticas nacionales.

De igual manera, en la década de 1930, la administración colonial francesa en África editó una serie de mapas regionales étnicos para definir su patrimonio cultural, sus formas de organización social y política, así como sus creencias y rituales. Esta recurrencia temática no deja lugar a dudas de que la expresión cultural de lo étnico es el sello de distinción de la antropología. No obstante, el uso que se le ha dado a este conocimiento ha sido diverso, desde la folclorización de las raíces identitarias hasta su utilización como referente de proyectos políticos contestatarios.

Las condiciones económicas, políticas y sociales en diferentes momentos históricos de cada país y su ubicación en el concierto del sistema mundial se reflejan en las múltiples orientaciones de la antropología. Como afirma Susana Narotzky en este texto: "sólo las formas hegemónicas de conocimiento se presentan a sí mismas como apolíticas" (p. 141). El resto de las antropologías está vinculado a proyectos políticos y se encuentra íntimamente asociado con relaciones de poder e inmerso en ocasiones en dilemas éticos.

El desenvolvimiento y los matices que ha tomado la antropología en diferentes partes del mundo están ligados a la institucionalización de regímenes particulares, trátese de intereses colonialistas o transnacionales, o bien de la necesidad de construir una identidad nacional o de poner distancia al control imperialista. Paul Nchoji nos ilustra sobre el caso de África comentando que, mientras ese continente estuvo integrado por colonias europeas, la antropología sirvió para cultivar el primitivismo o para hacer una apología de la presencia europea. Hoy día, los antropólogos africanos están más preocupados en que el conocimiento de sí mismos redunde en una superación de las condiciones marginales de sus jóvenes naciones. De manera contraria, la antropología japonesa surge como un proyecto nacional y se transforma en proyecto imperial. Actualmente se ve envuelta por fuerzas externas y evoluciona hacia un planteamiento pos-transnacional.

Como fundamento a un proyecto de construcción de nación, en este libro se ilustra la evolución de nuestra disciplina en países como México, India, España, la región andina y, de manera reciente, Francia. La antropología que se cultiva en estos países se ha remontado a la comprensión de su propia cultura y su sociedad. En ocasiones y en ciertos momentos de su 
historia también se ha planteado una perspectiva fuertemente emancipatoria, que incluso ha dado la oportunidad de concebir propuestas alternativas de conocimiento. Es en los casos latinoamericanos en los que aparece de manera más reiterativa el compromiso político que subyace en las prácticas antropológicas.

También podemos confirmar que la disponibilidad de recursos tanto físicos como humanos y simbólicos establece la diferencia. Como afirma Archetti en su texto: "La creación de instituciones con recursos apropiados está detrás de muchos milagros en el desarrollo de las ciencias sociales"(p. 132). Llama la atención en el capítulo sobre Gran Bretaña el énfasis puesto en las transformaciones de la vida académica, que se mueve al ritmo del incesante productivismo, de la continua evaluación, de la lucha por tener acceso a recursos, de la carga excesiva en actividades administrativas. El modelo neoliberal también ha atrapado al quehacer antropológico y, aunque no sea tan evidente en los otros casos presentados, bien sabemos que es una queja reiterativa en la mayoría de las comunidades académicas en el mundo entero.

Si bien el eficientismo trasciende fronteras y los reclamos en Gran Bretaña son similares a los que se viven en diferentes partes del mundo, incluyendo México, también encontramos en varios capítulos una suerte de reinvención de las prácticas de comunicación e intercambio entre las comunidades antropológicas del mundo. Entre las actividades que destacan están los congresos internacionales, el intercambio académico y las publicaciones conjuntas. Además, los avances de las tecnologías de la información nos han permitido establecer nuevos términos y condiciones en la generación de conocimiento, que se están instrumentando en el plano propiamente global. Antropólogos en diversas partes del mundo interactúan en tiempo real, tejiendo una densa red de reflexiones y oportunidades de colaboración que han trastocado la relación centro-periferia y el flujo unidireccional del conocimiento.

La antropología en diversas partes del mundo y en diferentes momentos históricos de las múltiples historias contadas en este libro ha desempeñado diferentes papeles. Estos papeles determinan las reflexiones epistemológicas y alientan las reflexiones éticas. La antropología, por lo tanto, se mantiene en un vaivén de encuentros y desencuentros.

Hay experiencias que se centran en la aplicación inmediata de su conocimiento para resolver problemas puntuales. El desarrollo de la antropología australiana y la africana se ha encauzado en un papel pragmático orientado a las consultorías y a la evaluación de proyectos, quehacer que ellos mismos denominan "la epistemología de encuentros breves" (p. 228). Esta orientación práctica de la antropología es vista con recelo por algunas comunidades académicas que consideran que hay una suerte de mercantilización de la disciplina, que sofoca la posibilidad de construir teorías.

La proyección de la antropología es más grande que la mencionada en el párrafo anterior cuando acompaña proyectos políticos de mayor envergadura, como lo son la penetración imperialista o la construcción de una nación. También en este libro encontramos una evolución más "aséptica" que podríamos denominar "antropología reflexiva”, cuyo propósito es generar conceptos que nos permitan comprender la realidad social y cultural de los diferentes pueblos o comunidades del mundo.

Una de las aportaciones importantes de World Anthropologies: Disciplinary Transformations within Systems of Power es la de dar la oportunidad para conocer la geopolítica de la generación de conocimiento antropológico, en la que se confirma una suerte de organización jerárquica de relaciones de dominación y subordinación, y que sólo en casos específicos ha dado lugar a procesos multidireccionados. En la obra se consignan varias trayectorias.

La trayectoria dominante se origina y desarrolla en Inglaterra, Francia y Estados Unidos, países que se convierten en centros hegemónicos en la formación de pensamiento antropológico. A estas escuelas de pensamiento antropológico se les atribuyen dos formas de colonización: una geográfi$\mathrm{ca}$, pues emprenden estudios en diversas partes del mundo, utilizando a los investigadores locales simplemente como informantes; y otra teórica, al ser los referentes obligados en las antropologías de casi todos los países aludidos en este texto.

La segunda trayectoria da cuenta de los avances científicos producidos en territorios no centrales que permanecen cautivos de lo local e invisibles ante la comunidad internacional. Para 


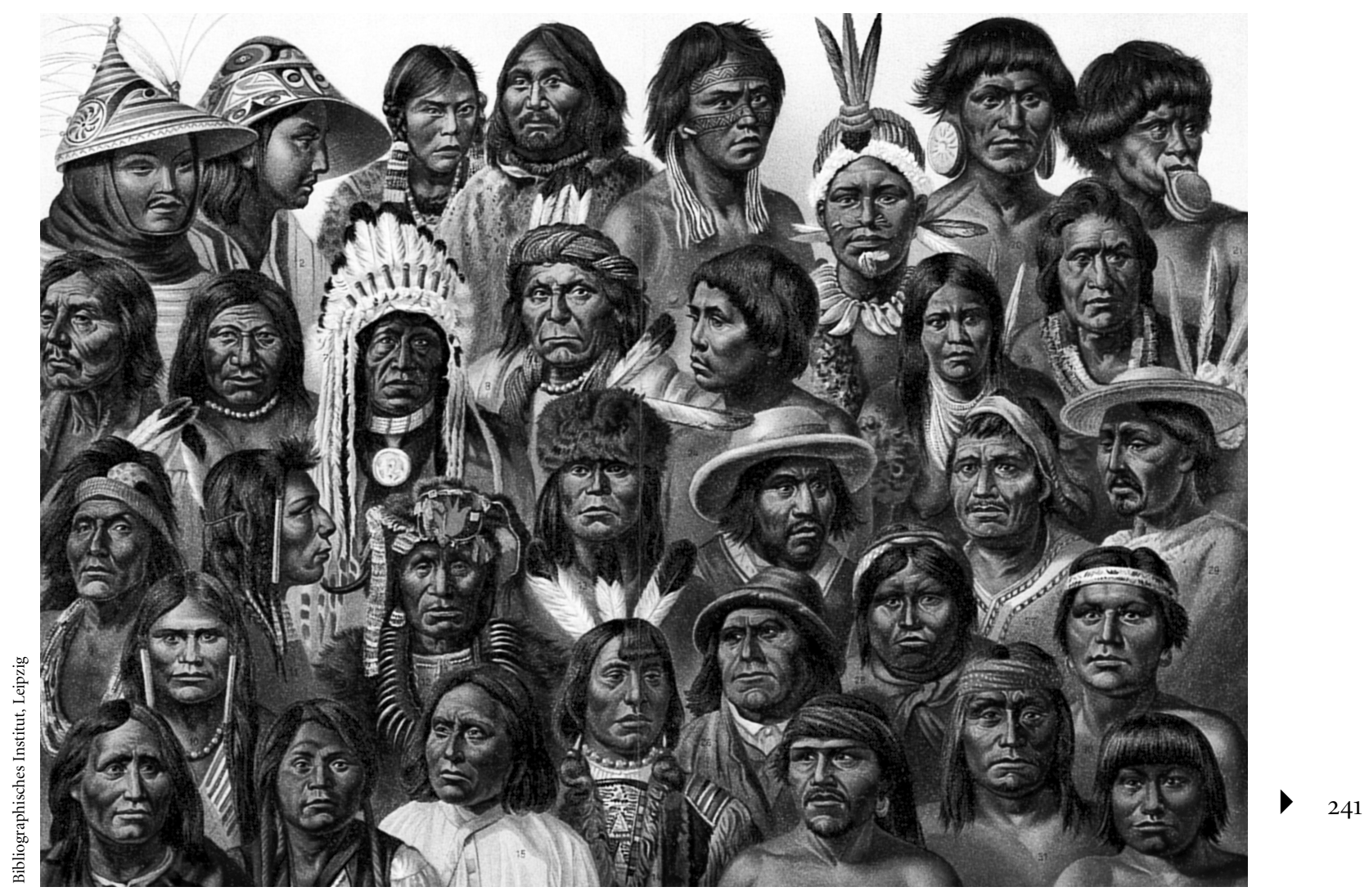

Nativos de América, en Nordisk familjebok (1904-1926).

sobreponerse a esta situación se ven obligados a satisfacer las expectativas del conocimiento central y mantener las referencias hegemónicas. Algunos ejemplos aquí mencionados son la antropología en Siberia, que en su origen recibió la influencia del pensamiento estadounidense a partir de una expedición realizada por Franz Boas al Pacífico Norte. El trabajo de algunos antropólogos mexicanos ha gozado de gran reconocimiento en el culturalismo estadounidense. También se menciona el impacto de la escuela estructural-funcionalista británica en España. Hubo también antropologías que se desarrollaron bajo presión ideológica. La misma antropología de Siberia experimentó esas censuras durante el régimen soviético, que obligaba a toda investigación de corte social a considerar el pensamiento marxista.

Estas dos trayectorias han provocado lo que Narotsky define como provincialismo metropolitano y que se refiere al desconocimiento en la antropología de Occidente de los conocimientos surgidos en lo que Krotz llama "las antropologías sin historia". Por otro lado, genera también el fenómeno del cosmopolitismo provincial.
Este último se apoya en la permanente referencia a y validación de "los clásicos", o sea, de la antropología occidental, y/o en la legitimación a partir del conocimiento hegemónico de lo generado en lo que se podría denominar como países periféricos.

La tercera trayectoria que encontramos en el libro es la producción de antropologías alternativas, en las que destaca el rompimiento con la dicotomía entre Occidente y Oriente. En la antropología japonesa se pone énfasis en esta circunstancia. Su comunidad, además, tiene la característica de ser una de las más grandes del mundo. 
Por último, la cuarta trayectoria que se vislumbra es aquélla que surge a partir del pensamiento crítico. Krotz, al presentar el caso de la antropología mexicana, argumenta que ésta es resultado de impulsos endógenos y exógenos, y que se ha moldeado a sí misma en su búsqueda por explicar y preservar la diversidad sociocultural del país y por respaldar la lucha de los pueblos indígenas por su autodeterminación. El caso andino ha tenido una respuesta similar ante el pensamiento dominante, al igual que la antropología brasileña, que tuvo como su referente principal a Paulo Freyre.

A pesar de que Latinoamérica presenta brotes no identificados con el discurso dominante y éstos pueden considerarse como centros alternativos de conocimiento, sus aportaciones son poco conocidas mundialmente. En algunos casos porque han sido escritas en español o portugués. Las barreras de lenguaje nos llevan a una de las reflexiones encontradas en la obra aquí aludida, que es la capacidad de difusión de la antropología producida en diferentes partes del mundo cuando no está escrita en inglés. El idioma anglosajón se ha convertido en la lengua franca de la producción de conocimiento.

La centralidad en el estudio de lo específico a partir de un enfoque cualitativo ha provocado que la antropología sea reconocida por otras ciencias sociales como tribal. Esta imagen es alimentada por enfoques cuantitativos, cuya supremacía y legitimidad en las últimas décadas es mantenida por quienes sólo consideran que un análisis es válido mientras pueda ser

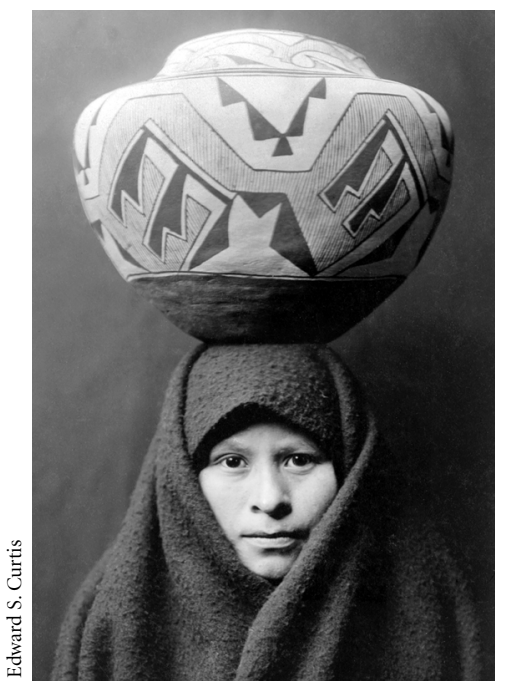

Joven zuni con jarrón, ca. 1903.

medible. Esto suscitó en algunos de los autores que participan en el libro la inquietud de que la antropología debería de protagonizar un diálogo con los referentes epistemológicos fundacionales de las ciencias sociales. Además, como afirma Marisol de la Cadena: "La antropología requiere mantener un proceso dialógico que permita navegar entre lo local y lo universal, entre las historias y la tendencia histórica, entre lo singular y lo general" (p. 221). Una ausencia reflexiva en esta obra es la del diálogo con otras disciplinas. La inter y la transdisciplina deberían estar en la agenda de futuros encuentros para quitarnos la imagen endogámica.

Este libro representa una gran aportación para la comunidad antropológica mundial. No obstante, los editores mencionan que es uno de los tantos logros de un proyecto a largo plazo, cuyo propósito es constituir un foro abierto en el que las antropolo- gías del mundo se mantengan en permanente diálogo bajo el principio de la inclusión y el respeto por la diversidad. Hay un gran interés por resaltar la necesidad de sustituir el monopolio del conocimiento por el reconocimiento de la producción antropológica heterogénea y policéntrica.

Como se mencionó anteriormente, el énfasis puesto en la construcción de redes cibernéticas está presente en varios de los capítulos. Hay algunos ejemplos que vale la pena recalcar: la ya constituida red de las antropologías del mundo (<www.ram-wan.org $>$ ), que desde 2003 permite el encuentro $y$ la recreación de nuevos horizontes para nuestra disciplina. Además, estas redes han permitido la organización de conferencias y congresos y la integración de asociaciones, entre las que destaca la creación del World Council of Anthropological Association $(<$ www.wcaanet.org.br $>$ ). Todos estos esfuerzos constituyen espacios en pos de la construcción de una densa red que permita la concurrencia más allá de las prácticas institucionales en el plano local y que coadyuve a aprovechar el potencial de la diversidad del quehacer antropológico, a la vez que fomente el sentido de unidad y fuerza de la disciplina a nivel global. Como afirman los editores de esta obra en su capítulo introductorio: "Creemos que con la globalización se le han abierto oportunidades heterodoxas al mundo académico. Opinamos que por medio de la acción política concertada puede cobrar existencia una comunidad de antropólogos heteroglósica, democrática y transnacional" (p. 2).

febrero de 2007 